\title{
Interconnection Between Information Mechanism on Crowdfunding Platforms and Product Launch Decision on the Market: Case Study of ASEAN-Five Countries
}

\author{
Farah Yumna, Liyu Adhi Kasari Sulung* \\ Department of Management, Universitas Indonesia, Depok, Indonesia \\ *Corresponding author. Email: liyu.as@gmail.com
}

\begin{abstract}
Crowdfunding activities not only help initiators to obtain funding, but also to give the information valuation to the project initiators for minimizing product default risk in the market. This study investigated the Kickstarter platform as a resource in Singapore, Malaysia, Indonesia, Thailand, and Philippine (ASEAN 5 Countries). To get the results of the analysis, we used probit regression and the average marginal effect in processing data. There are five independent variables; information mechanism presented by average pledge, the number of backers, pledge ratio, and total pledge. And the community which used to see the effect and probability of the dependent variable of the study.
\end{abstract}

Keywords: Crowdfunding, Beyond Financing, Information Mechanism, Product Release

\section{INTRODUCTION}

In the last decade, the crowdfunding phenomenon become a trend on entrepreneurs sites, especially in the small and medium enterprises category. Crowdfunding is funding method that used an online platform for a project initiator to meet the society (Lebraty and LobreLebraty, 2013). Crowdfunding activities certainly make it easier for project initiators, especially in the small and medium entrepreneurs category to get funding quickly, easily and with lower risk. However, crowdfunding activities are not always in accordance with the target, especially for crowdfunding activities initiated by small and medium enterprises. In crowdfunding activity, the success condition happens if the total pledge collected by the backers in a certain period of time is equal to or higher than the goal determined by the project initiator (Schwienbacher, 2017) while the unsuccess condition is if the total pledge collected by the supporters is lower than the predetermined delivery target (Greenberg et al, 2013). One of the factors that influence the success rate of a crowdfunding project is the evaluation of the quality of products by backers. Product quality is illustrated through the information available on crowdfunding platforms and other information channels, initiator's activities during crowdfunding campaigns, and ideas raised on projects to be developed. From that perspective, backers play a role as the venture capitalist or conventional financial institutions because they evaluate the quality of the product and crowdfunding projects (Gorman and Shalman, 1989; McMillan, 1986).

Howoever, even though the success of a project can be influenced by the quality of a good project, it does not mean that a failed project has a worse level of quality. Some projects which have a lower level of quality can still reach the funding target. This happens because the funding target determined by the project initiator is low, thus the project can easily exceed its funding target (Mollick, 2014). Studies that discuss the real success rate of crowdfunding activities defined by product release are quite rare. Therefore this provides added value through investigating the probability of a project initiator deciding to launch a product even though the crowdfunding activity carried out does not reach the funding initiator's target.

Crowdfunding activities are used not only to collect funding, but also to see the enthusiasm of the backers toward the project. Moreover, project initiators try to build a community to create consumer loyalty (Stanko and Henard, 2019). Therefore, the community is one of the important components to show the quality of the project and facilitate creating a successful business 
(Crosetto, 2018). Based on previous research, the community contributes to the decision of project initiators to carry out product launches. Thus, this study considered this added value.

\section{LITERATURE REVIEW}

\subsection{Crowdfunding}

Crowdfunding's presence in the funding industry is the initial step for entrepreneurs, especially the small and medium enterprises, in getting funding support more easily (Viotto, 2018). Crowdfunding shares the same concept as crowdsourcing, as it oriented towards "open call" activities through the Internet to create a collection of people who want to contribute to the company's operations (Howe, 2008). Fundraising carried out by backers is one of the most important elements in crowdfunding activities, this condition shows that backers have actively contributed to creating and developing a crowdfunding project (Belleflamme et al, 2010). Backers provide an opportunity for initiators to study consumer preferences, which then benefits the initiator in creating project success in crowdfunding (Chemla and Tinn, 2017).

Reward-based crowdfunding is a crowdfunding method that provides gifts to backers who contribute to the project created by the initiator (Davis et al, 2017). The benefits of reward-based crowdfunding method for backers are the provision of products an earlier time, lower prices, and more attractive prizes (Mollick, 2014). Reward-based crowdfunding also allows product differentiation based on the level of rewards (Crosetto, 2018). Until now reward-based crowdfunding garners the most interest by providing physical and non-physical rewards.

Fixed funding is one of the mechanisms used in reward-based crowdfunding. The fixed funding mechanism is a method that has a high risk for the initiator of the project because the funds collected by backers will be returned if the project cannot reach the funding target (Cumming et-al., 2019). Fixed funding provides a higher profit for a project compared to flexible funding (Cornelli, 1996), because the fixed funding mechanism can reinforce incentives by giving refunds to backers when the quality of the product is considered poor, so the probability of the project getting more funding is higher (Chang et-al., 2016).

\subsection{Product Release in Retail}

Some uncertain elements arise when an initiator issues a product, thus it is not uncommon for many new products to not last long on the market (Asplund, 1999). Therefore, when the initiator invests in a new product, they must be consider many factors that must be considered to determine the condition of the product in the future, such as consumer preferences and the difficulty of introducing new products in an everexpanding industry. Crowdfunding not only provides funding benefits but also information valuation to see the sustainability of new product on the market, which will help the initiators in reducing the risk level of product uncertainty (Asplund, 1999).

Previous research, has shown a positive relationship between the project campaign on crowdfunding platforms and the initiator's decision to make product launches in the market, even when the crowdfunding campaigns did not get sufficient funding in crowdfunding activities. The reason the initiator still believes that the product will be accepted in the market is because of the valuation information obtained through crowdfunding platforms.

\subsection{Information Mechanism}

In crowdfunding activities, the product are analyzed by backers as initial consumers who have high levels of preference and credibility. The preference given by backers generates public information about potential product demand on the market when the product is launched (Schwienbacher, 2015). Usually the generated information is related to market demand valuation, society's contribution to the product, individual appreciation of the product and product value from consumer's perspective compared to initiator's perspective (Viotto, 2018). This will help the project initiator decide on of the product's launch (Chemla and Tinn, 2017).

Some advantages are gained by the project initiator from the information obtained through the project campaign on crowdfunding platform regarding: (1) the number of backers who contribute to the success of the crowdfunding project; (2) the amount contributed by each backer; (3) the crowdfunding project appreciation given by the backers; (4) and the amount raised by backers' contribution to the crowdfunding project compared to the crowdfunding target chosen by the project initiator (Viotto, 2018). All variables stated before are the basis for the decision making of the initiator, and the advantage gained by the project initiator from the usage of those variables is the information related to the product's market valuation (Viotto, 2018).

In measuring market potential, initiators use the backer's response during the crowdfunding campaign (Ramsey, 2012). By using campaigns and activities carried out during crowdfunding, the initiators can attract many backers to contribute the crowdfunding campaign (Valencience, 2013). The more backers who participate in a crowdfunding project, the more individuals will consume the products. This condition occurs because the number of backers has an influence 
on the market performance based on projects initiated on crowdfunding platforms (Stanko and Henard, 2017). Backers are used as a representation of consumers, thus project initiators use crowdfunding activities as a benchmark for market performance and product enthusiasm. Thus, it can be concluded that the higher is the number of backers, the greater is the probability of the project initiator will release a product. Therefore:

H1: The number of backers has a positive influence on the initiator's decision to release a product.

The value given by a backer of a crowdfunding project can be calculated by dividing the total pledge by the number of contributing backers, which is also called the average pledge. This shows how much is appreciation given by each backer on a crowdfunding project. We also compared the total pledge given by backers to the target of appreciation expected by the project initiator, which is called pledge ratio. The average pledge is an individual valuation used by the initiator in assessing crowdfunding projects (Mollick, 2014; Viotto, 2018), and pledge ratio is used as a benchmark of the contribution that is associated with the goal of crowdfunding projects and can be seen as the potential of releasing the product (Petitjean, 2017). The higher are the values of the average pledge and pledge ratio, the higher is the probability of releasing a product (Viotto, 2018). Therefore:

H2: The average pledge and pledge ratio given by backers have a positive influence on the initiator's decision to release a product.

The contribution provided by backers to a project not only affect the success of the project in crowdfunding activities but also show how much backers appreciate the project (Viotto, 2018). Total pledge given by backers has a positive influence on the probability in getting funding from other backers (Roma et al, 2017). The total pledge is also shown an indication relates to the market potential of the crowdfunding project (Roma et al, 2017). The higher the total pledge, the higher is the probability of releasing a product. Therefore:

H3: Total pledge given by backers have a positive influence on the initiator's decision to release a product.

\subsection{Community}

In expanding the social network, a project initiator could use social media to create the community (Borst et al, 2017). The role of social media in crowdfunding campaign is to expand the community network and backers network to contribute to the campaign, which will affect the success rate of the campaign itself ( $\mathrm{Lu}$ et al, 2014). Previous studies have found that the number of friends on the initiator's Facebook affect almost $40 \%$ of crowdfunding project's success rate (Mollick, 2014). Social media has a role for

minimizing the information failures between the project initiator and the backers (Lu et al, 2014). When the community has a lot of people to support and encourage information regarding products to be launched, this will have a positive effect on the initiator's decision to be able to release a product. Therefore:

H4: FB Fans have a positive influence to initiator's decision to release a product.

\section{RESEARCH METHODOLOGY}

\subsection{Data}

This research used the population of crowdfunding projects on the Kickstarter platform in ASEAN-five countries, i.e. Indonesia, Malaysia, Thailand, Philippine, and Singapore. The data are based on the five top categories of crowdfunding project in ASEAN-five countries; design, fashion, games, film \& video, and technology. We used ASEAN-five countries because this area has the potential for increasing economic condition with the distribution of financial technology used (EY, 2018).

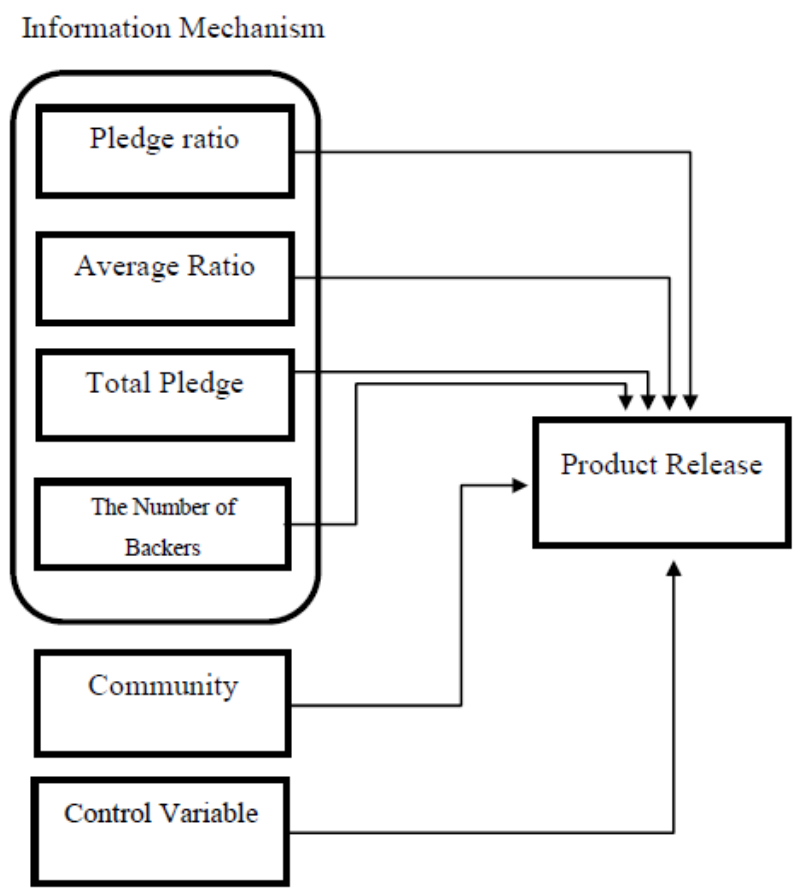

Figure I. Model Illustration

\subsection{Sampling Method}

There is a criterion that must be met on crowdfunding projects, thus we used a purposive sampling technique to assist in classifying the research data. Purposive sampling is a technique of selecting 
research data by sampling according to predetermined criteria (Cooper \& Schindler, 2014). The criterion that must be met in this study is the attachment of social media links listed on the crowdfunding project page. The project population in ASEAN-five countries on Kickstarter platform is 1728 , and for project population in the five researched industries is 1183 . The researchers took data from the beginning of 2017 to the beginning of 2019. The reason researchers took samples from the last two years was that the regulations and the investments made by the government in Southeast Asia on financial technology markets began to grow in that year. Projects that were used as research data completed their campaign period, both for successful and failed to be funded projects. These projects benefit backers in the form of gifts that have been promised during the campaign period. Backers will get the reward according to the time determined by the initiator on the funding package attached in the crowdfunding project.

\subsection{Research Variables}

According to the theoretical framework and model described before, Table I contents are the definition of variables and hypotheses related to the model.
Table I. Variables Description

\begin{tabular}{|c|c|c|}
\hline $\begin{array}{l}\text { Type of } \\
\text { Variable }\end{array}$ & $\begin{array}{l}\text { Name of } \\
\text { Variable }\end{array}$ & Description \\
\hline $\begin{array}{l}\text { Dependent } \\
\text { Variable }\end{array}$ & $\begin{array}{l}\text { Product } \\
\text { Release }\end{array}$ & $\begin{array}{l}\text { Dummy variable, } 1 \text { if the project can } \\
\text { release the product in retail, } 0 \text { if not. }\end{array}$ \\
\hline \multirow[t]{4}{*}{$\begin{array}{l}\text { Independent } \\
\text { Variable }\end{array}$} & $\begin{array}{l}\text { Total } \\
\text { Pledge }\end{array}$ & $\begin{array}{l}\text { The number of funding gathered by } \\
\text { backers. }\end{array}$ \\
\hline & $\begin{array}{l}\text { Pledge } \\
\text { Ratio }\end{array}$ & $\begin{array}{l}\text { The number of funding gathered by } \\
\text { backers divided by funding goals set } \\
\text { by project initiator. }\end{array}$ \\
\hline & $\begin{array}{l}\text { Average } \\
\text { Pledge }\end{array}$ & $\begin{array}{l}\text { The number of funding gathered by } \\
\text { backers divided by the number of } \\
\text { backers participated. }\end{array}$ \\
\hline & $\begin{array}{l}\text { The number } \\
\text { of backers }\end{array}$ & The number of backers participated. \\
\hline \multirow[t]{6}{*}{$\begin{array}{l}\text { Control } \\
\text { Variable }\end{array}$} & $\begin{array}{l}\text { Funding } \\
\text { Goal }\end{array}$ & $\begin{array}{l}\text { Amount set by initiator as a funding } \\
\text { limit of the project, }\end{array}$ \\
\hline & $\begin{array}{l}\text { Previous } \\
\text { Product }\end{array}$ & $\begin{array}{l}\text { The number of projects that have } \\
\text { been carried out by the initiator } \\
\text { before the project that used for } \\
\text { observation. }\end{array}$ \\
\hline & $\begin{array}{l}\text { Production } \\
\text { Phase }\end{array}$ & $\begin{array}{l}\text { Time needed by the project initiator } \\
\text { to carry out the production process. }\end{array}$ \\
\hline & $\begin{array}{l}\text { Spelling } \\
\text { Error }\end{array}$ & $\begin{array}{l}\text { The number of errors in writing } \\
\text { product descriptions. }\end{array}$ \\
\hline & $\begin{array}{l}\text { Word } \\
\text { Count }\end{array}$ & $\begin{array}{l}\text { The number of words in product } \\
\text { descriptions. }\end{array}$ \\
\hline & $\begin{array}{l}\text { Backer } \\
\text { Sentiment }\end{array}$ & $\begin{array}{l}\text { the ratio of positive and negative } \\
\text { comments. }\end{array}$ \\
\hline
\end{tabular}

Those control variables are usually used for interpreting the quality of the project (Mollick, 2014), as they help the backers to give a valuation for the crowdfunding's project. The funding goal was used for controlling the size, the previous product and the production phase were used for controlling market quality and for the spelling error, word count and backer sentiment were used for controlling the project quality. 


\subsection{Research Model}

There are four specifications for the research model. Based on Table II, they are separated by information mechanism variables.

Table II. Model Specification

\begin{tabular}{|l|l|}
\hline Description & \multicolumn{1}{|c|}{ Model Specification } \\
\hline $\begin{array}{l}\text { Information Mechanism } \\
\text { with Total Pledge }\end{array}$ & $\begin{array}{l}\operatorname{Pr}(\text { release }=1 \mid \mathrm{x})=\Phi\left(\beta_{0}+\beta_{1} \log _{1}+\right. \\
\left.\beta_{2} \log _{\mathrm{i}}+\psi_{\mathrm{t}}+\varepsilon\right)\end{array}$ \\
\hline $\begin{array}{l}\text { Information Mechanism } \\
\text { with Average Pledge }\end{array}$ & $\begin{array}{l}\operatorname{Pr}(\text { release }=1 \mid \mathrm{x})=\Phi\left(\beta_{0}+\beta_{1} \log _{\mathrm{AP}}\right. \\
\left.+\beta_{2} \operatorname{LogC}_{\mathrm{i}}+\psi_{\mathrm{t}}+\varepsilon\right)\end{array}$ \\
\hline $\begin{array}{l}\text { Information Mechanism } \\
\text { with The Number of } \\
\text { Backers }\end{array}$ & $\begin{array}{l}\operatorname{Pr}(\text { release }=1 \mid \mathrm{x})=\Phi\left(\beta_{0}+\beta_{1} \operatorname{LogBa}_{1}\right. \\
\left.+\beta_{2} \log _{\mathrm{i}}+\psi_{\mathrm{t}}+\varepsilon\right)\end{array}$ \\
\hline $\begin{array}{l}\text { Information Mechanism } \\
\text { with Pledge Ratio }\end{array}$ & $\begin{array}{l}\operatorname{Pr}(\text { release }=1 \mid \mathrm{x})=\Phi\left(\beta_{0}+\beta_{1} \mathrm{PR}_{1}+\right. \\
\left.\beta_{2} \operatorname{LogC}_{\mathrm{i}}+\psi_{\mathrm{t}}+\varepsilon\right)\end{array}$ \\
\hline
\end{tabular}

\subsection{Research Methodology}

First, researcher did Akaike's Information Criteria and Bayesian Information Criteria tests to know which methodology we used between probit and logit. After that, the researcher did the specification test or link test for measuring whether the model has been perfectly specified or not.

According to Table III, the values of AIC and BIC test for probit regression are lower than logit regression, even though the difference between them are not really high. This shows that the model with probit regression better explains the actual conditions compared to logit regression.

Table III. AIC and BIC Results

\begin{tabular}{|l|l|l|l|l|}
\hline & \multicolumn{2}{|l|}{ Model I } & \multicolumn{2}{l|}{ Model II } \\
\hline & Logit & Probit & Logit & Probit \\
\hline AIC & 0,739 & 0,734 & 0,745 & 0,741 \\
\hline BIC & $-1308,731$ & $-1310,114$ & $-1307,196$ & $-1308,153$ \\
\hline & Model III & Model IV \\
\hline AIC & 0,769 & 0,766 & 0,772 & 0,771 \\
\hline BIC & $-1300,553$ & $-1301,426$ & $-1299,814$ & $-1299,920$ \\
\hline
\end{tabular}

If the _hatsq value is not significant and the _hat value is significant at $1 \%, 5 \%$, and $10 \%$, then the model has well explained the actual model. Based on the results in Table IV of the link test it is known that the _hat values and _hatsq values are appropriate, so the model is in accordance with the actual conditions.
Table IV. Link Test Result

\begin{tabular}{|l|l|l|l|l|}
\hline & I & II & III & IV \\
\hline _hat & $0,020^{* *}$ & $0,006^{* * *}$ & $0,084^{*}$ & $0,020^{* *}$ \\
\hline _hatsq & 0,143 & 0,374 & 0,277 & 0,880 \\
\hline _cons & 0,936 & 0,955 & 0,781 & 0,947 \\
\hline
\end{tabular}

\section{RESULTS}

Descriptive statistics in Table $\mathrm{V}$ are used to determine the characteristics of crowdfunding project data in conducting research. The data are projects that has been funded by backers starting from the ending period of 2017 to the beginning of January 2019. In total, crowdfunding projects were used as research data.

Table V. Statistic Description

\begin{tabular}{|l|l|l|l|l|}
\hline Variable & Mean & Std. Dev & Min & Max \\
\hline Retail & 0,84 & 0,3673 & 0 & 1 \\
\hline Total Pledge & 36855,1 & 89728,09 & 1 & 842426 \\
\hline Backers & 240,31 & 658,82 & 1 & 7385 \\
\hline Average pledge & 238,60 & 883,23 & 1 & 14293,1 \\
\hline Pledge ratio & 2,2283 & 5,0777 & $1,54 \times$ & 53,71 \\
\hline Prev & & & $10-7$ & \\
\hline Product & 0,5418 & 1,1467 & 0 & 8 \\
\hline Prod Phase & 3,2025 & 2,8901 & 0.033 & 21.6 \\
\hline Success & 0,6182 & 0,4867 & 0 & 1 \\
\hline Goals & 24767,2 & 36310,89 & 13,35 & 300000 \\
\hline FB Fans & 3338,85 & 11545,62 & 1 & 129226 \\
\hline Spelling Error & 5,6218 & 5,6628 & 0 & 30 \\
\hline Words & 897,24 & 641,70 & 49 & 3819 \\
\hline Backer Sent & 0,3594 & 0,3816 & 0 & 1 \\
\hline
\end{tabular}


Table VI. Probit Regression Result

\begin{tabular}{|c|c|c|c|c|}
\hline & I & II & III & IV \\
\hline$\overline{\log _{-} P_{i}}$ & $\begin{array}{l}0,195 * * * \\
(0,051)\end{array}$ & & & \\
\hline$\overline{\log _{-} \mathrm{AP}_{\mathrm{i}}}$ & & $\begin{array}{l}0,335 \text { *** } \\
(0,096)\end{array}$ & & \\
\hline Log_Ba & & & $\begin{array}{l}0,172 * * \\
(0,068)\end{array}$ & \\
\hline $\mathrm{PR}_{\mathrm{i}}$ & & & & $\begin{array}{l}0,146^{*} \\
(0,081)\end{array}$ \\
\hline $\log _{-} C_{i}$ & $\begin{array}{l}0,259 * * * \\
(0,060)\end{array}$ & $\begin{array}{l}0,295^{* * * *} \\
(0,061)\end{array}$ & $\begin{array}{l}0,274 * * * \\
(0,061)\end{array}$ & $\begin{array}{l}0,292^{* * * *} \\
(0,060)\end{array}$ \\
\hline$\overline{\mathrm{PP}_{\mathrm{i}}}$ & $\begin{array}{l}0,043 \\
(0,128)\end{array}$ & $\begin{array}{l}0,115 \\
(0,133)\end{array}$ & $\begin{array}{l}0,072 \\
(0,133)\end{array}$ & $\begin{array}{l}0,076 \\
(0,136)\end{array}$ \\
\hline $\mathrm{PPh}$ & $\begin{array}{l}-0,052 \\
(0,036)\end{array}$ & $\begin{array}{l}-0,035 \\
(0,035)\end{array}$ & $\begin{array}{l}-0,039 \\
(0,036)\end{array}$ & $\begin{array}{l}-0,024 \\
(0,035)\end{array}$ \\
\hline Log_Goal & $\begin{array}{l}-0,041 \\
(0,072)\end{array}$ & $\begin{array}{l}-0,063 \\
(0,076)\end{array}$ & $\begin{array}{l}0,004 \\
(0,071)\end{array}$ & $\begin{array}{l}0,069 \\
(0,077)\end{array}$ \\
\hline Sentiment & $\begin{array}{l}0,221 \\
(0,285)\end{array}$ & $\begin{array}{l}0,369 \\
(0,289)\end{array}$ & $\begin{array}{l}0,174 \\
(0,279)\end{array}$ & $\begin{array}{l}0,275 \\
(0,275)\end{array}$ \\
\hline $\begin{array}{l}\text { Word } \\
\text { Count }\end{array}$ & $\begin{array}{l}-0,001 \\
(0,001)\end{array}$ & $\begin{array}{l}-0,001 \\
(0,001)\end{array}$ & $\begin{array}{l}-0,001 \\
(0,001)\end{array}$ & $\begin{array}{l}-0,001 \\
(0,001)\end{array}$ \\
\hline Spelling & $\begin{array}{l}0,006 \\
(0,023)\end{array}$ & $\begin{array}{l}0,006 \\
(0,023)\end{array}$ & $\begin{array}{l}0,012 \\
(0,023)\end{array}$ & $\begin{array}{l}0,015 \\
(0,023)\end{array}$ \\
\hline Constant & $\begin{array}{l}-1,435 \\
(0,686)\end{array}$ & $\begin{array}{l}-1,535 \\
(0,722)\end{array}$ & $\begin{array}{l}-1,083 \\
(0,658)\end{array}$ & $\begin{array}{l}-1,496 \\
(0,733)\end{array}$ \\
\hline Obse & 275 & 275 & 275 & 275 \\
\hline LR chi2 & (8)57,87 & (8)55,91 & (8)49,18 & (8)47,68 \\
\hline Prob chi2 & 0,0000 & 0,0000 & 0,0000 & 0,0000 \\
\hline $\begin{array}{l}\text { Pseudo } \\
R 2\end{array}$ & 0,2393 & 0,2312 & 0,2034 & 0,1972 \\
\hline
\end{tabular}

\subsection{Regression Test Results}

Four different models are presented in Table VI; the first model uses the total pledge variable as a representation of the information mechanism; the second model uses the average pledge variable as a representation of the information mechanism; the third model uses the number of backers variable and the last model uses the pledge ratio variable.

\subsection{Average Marginal Effect Test Result}

In explaining the results of the probit regression coefficient in Table VII, an average marginal effect test is needed. We used the average marginal effect to significantly see the average change in probability of the independent variable on the dependent variable.

\subsection{Discussion}

For the first hypothesis, from the results of probit regression, it is known that the number of backers has a positive and significant effect on the research model. The probability of releasing a product decision when the number of backers increases by $10 \%$ on average changes by 0.331 percentage points. This condition explains that the more backers contribute to crowdfunding projects, the greater the possibility of project initiators in releasing a product. The initiator can quantify the potential of a product on the market through the response given by backers during crowdfunding activities. Through these campaigns and activities, project initiators can attract a lot of attention from backers to contribute to crowdfunding campaigns (Valanciene, 2013). This result is consistent with the previous research, which explained that the number of backers has an influence on market performance related to projects that are measured through crowdfunding platforms. Thus, it can be concluded that backers are consumers' representation in the market so that the project initiator uses crowdfunding activities as a measure of performance and product enthusiasm on the market.

For second hypothesis, based on the results, the average pledge and pledge ratio have a positive relationship with the dependent variable. The probability changes of the project initiator's decision to release the product after crowdfunding increases by an average of 0.623 percentage points for an average pledge increase of $10 \%$ and 2.87 percentage points on average increased of the pledge ratio by 1 . From this result, a high valuation level will represent a better market condition so the possibility of product failure risk in the market will decrease.

For the third hypothesis, based on the results, the total pledge has a significant and positive effect on the dependent variable. The probability changes on the dependent variable also increased by an average of 0,357 percentage points per increase in the total pledge by $10 \%$. The total pledge can explained as one of the conditions to see how much backers are described as consumers on the market gives the value for a project (Viotto, 2018). Moreover, the project initiator can use the total pledge as a reference for the funding target that must be determined when the project fails. Thus, the conclusion is the higher is the total pledge obtained by 
the project initiator, the higher is the probability of releasing the product to market.

Table VII. Average Marginal Effect Result

\begin{tabular}{|l|l|l|l|l|}
\hline & I & II & III & IV \\
\hline Log_P & $\begin{array}{l}0,035^{* * *} \\
(0,007)\end{array}$ & & & \\
\hline Log_AP & & $\begin{array}{l}0,062^{* * *} \\
(0,016)\end{array}$ & & \\
\hline Log_Bai & & & $\begin{array}{l}0,0331^{* * *} \\
(0,012)\end{array}$ & \\
\hline PRi & & & $0,028^{*}$ \\
\hline Log_C & $\begin{array}{l}0,047^{* * *} \\
(0,01)\end{array}$ & $\begin{array}{l}0,054^{* * *} \\
(0,01)\end{array}$ & $\begin{array}{l}0,053^{* * *} \\
(0,01)\end{array}$ & $\begin{array}{l}0,057^{* * *} \\
(0,01)\end{array}$ \\
\hline
\end{tabular}

For the forth hypothesis, based on the results, the FB fans have a significant and positive influence on to the decisions of project initiators to release the product. The probability changes for the initiator's decision increased by an average of 0.5 percentage points for each model per FB fans by $10 \%$. The community incorporated in a social media will exchange information relate to the project being discussed, thus creating a new perception for the community. With the emergence of new perceptions, the community will act as consumers who are loyal to the product by making repeated purchases (Lu et al, 2014). Loyal customers have a desire to consume these products continually and for a long time.

\section{CONCLUSION}

We found that the four independent variables describing the information mechanism had a significant and positive effect in ASEAN-five countries' crowdfunding projects. This condition answers several assumptions and theories that have been stated previously, as the number of backers can be used as real consumers representation in the market, the total pledge that indicates a positive signal related to the market potential of the crowdfunding project, average pledge and pledge ratio, explain the personal valuation of the backer. This helps project initiators make decisions related to product launches. Project initiator must be more confident when they want to release a product in the market after getting good information mechanism valuation from the backers.

In addition to the information mechanism, the community in social media also has an influence on the decisions of initiators in releasing the product to market. Social media such as Facebook can be used to disseminate information related to crowdfunding activities on a project. This information will create a positive new perception to increase consumer loyalty in repeating product purchases ( $\mathrm{Lu}$ et al, 2014). When the number of communities on social media is high, the project initiator will tend to feel safe about the product that will be launched. Thus, the conclusion is the community has a consistent influence on the initiator's decision to release the product.

\section{RESEARCH LIMITATION}

There must be many variables that can be used to measure the decision of the project initiator to release a product on the market. Using the secondary data provides limited knowledge for researchers to explore the factors that influence the initiator's decision to release a product on the market. Besides, this research is only carried out on a reward-based platform, thus it can not represent other crowdfunding methods such as debtbased crowdfunding, and equity-based crowdfunding.

\section{REFERENCES}

[1] Asplund, M., Sandin, R., 1999. The Survival of New Product. Review of Industrial Organization 15 (3), 219-237

[2] Belleflamme, P., Lambert, T., Schwienbacher, A., 2010. Crowdfunding: An Industrial Organization Perspective. In Prepared for the workshop Digital Business Models: Understanding Strategies', 2526).

[3] Borst, Irma, Moser, Christine, Ferguson, Julie, 2017. From friend-funding to crowdfunding: relevance of relationships, social media, and platform activities to crowdfunding performance. New Media Soc. 38, 1-19.

[4] Chang, J. W., 2016, The Economics of Crowdfunding. Available at SSRN 2827354.

[5] Chemla, G., Tinn, K., 2017. Learning through Crowdfunding.

[6] Cooper, D. R., Schindler, P. S., 2014. Business research methods: Mc Graw-Hill/Irwin

[7] Cornelli, F., 1996. Optimal Selling Procedures with Fixed Costs. Journal of Economic Theory 71 (1), 130.

[8] Crosetto, P., Regner T., 2018. It's never too late: Funding dynamics and self pledges in rewardbased crowdfunding. Research Policy, 47(8), 14631477

[9] Cumming, D. J., Leboeuf, G., \& Schwienbacher, A., 2019. Crowdfunding models: Keep-It-All vs. All-or-Nothing. Dostupno na: https://www. eurofidai. org/Schwienbacher_2014. pdf [22.02. 2017.]. 
[10] Davis, B.C., Hmieleski, K. M., Webb, J. W., \& Coombs, J. E., 2017. Funders' positive affective reactions to entrepreneurs' crowdfunding pitches: The influence of perceived product creativity and entrepreneurial passion. Journal of Business Venturing, 32(1), 90-106.

[11] EY General Fintech Enquiries, 2017. State of FinTech in ASEAN.

[12] Gorman, M., Sahlman W. A., 1989. What do Venture Capitalists Do?. Journal of Business Venturing, 4 (4), 231-248.

[13] Greenberg, M. D., Pardo, B., Hariharan, K., and Gerber, R., 2013. Crowdfunding support tools: Predicting success and failure. Human Factor in computing system. 1815-1820.

[14] Howe, J., 2008. Crowdsourcing: Why the power of crowd is driving future of Business. New York: Three Rivers Press.

[15] Lebraty and Lobre-Lebraty, 2013. Crowdsourcing for Heritage: The Changing Role of the UK Heritage Sector.

[16] Lu, Chun-Ta., Xie, S., Kong, X., Yu, P.S., 2014. Inferring the impacts of Social Media on Crowdfunding. In Proceedings of the 7th ACM international conference on Web search and data mining (pp. 573-582). ACM.

[17] McMillan, D. W., Chavis, D. M., 1986. Sense of Community: A Definition and Theory. Journal of Community Psychology 14 (1), 6-23
[18] Mollick, E., 2014. The dynamics of crowdfunding: an explanatory study. Journal of Business Venturing. 29 (1), 1-16.

[19] Petitejean M., 2017. What explain the success of reward-based crowdfunding campaign as they unfold? Evidence from the French crowdfunding platform KissKissBankBank. Finance research letter 26. 9-14.

[20] Ramsey, Y. A., 2012. What the heck is crowdfunding? Business people, November, p. 5457.

[21] Roma, P., Petruzzelli, A., M., Perrone, G., 2017. From the crowd to the market: The role of rewardbased crowdfunding performance in attracting professional investors. Research Policy. 46 (9) 1606-1628.

[22] Schwienbacher, A. 2017. Entrepreneurial risktaking in crowdfunding campaigns. Small Business Economics ,. 51(4), 843-859.

[23] Stanko, M.A., \& Hennard, D.H., 2017. Toward a better understanding of crowdfunding, openness and the consequences for innovation. Research Policy, 46(4), 784-798.

[24] Valanciene, L., Jegeleviciute, S., 2013. Valuation of Crowdfunding: Benefit and Drawbacks. Economics and Management, 18(1), 39-48.

[25] Viotto J., 2018. Beyond Financing: Crowdfunding as an informational mechanism. Journal of Business Venturing. 33(3), 371-393. 